\title{
THE NORMAL DURATION OF THE ELECTROCARDIOGRAPHIC VENTRICULAR COMPLEX
}

\author{
BY WRIGHT ADAMS \\ (From the Department of Medicine, University of Chicago, Chicago)
}

(Received for publication February 8, 1936)

The duration of ventricular systole has aroused the interest of a number of workers since Garrod pointed out its relation to the heart rate in 1871 . The duration of systole has been measured by various vascular, intracardiac, and apical pressure records, heart sound records and combinations of these, the work of Wiggers and Katz (1) and Lombard and Cope (2) furnishing an introduction to this literature. Venous pressure, arterial pressure, posture, exertion, nervous influences and drugs have been found to modify it experimentally. Cheer and $\mathrm{Li}$ (3), Bartos and Burstein (4), Bazett and Sands (5) and others have investigated the relation of the duration of the electrocardiographic ventricular complex to the duration of systole and have found them to be closely related but not identical. The most accurate mechanical means for measuring the duration of systole are not applicable to clinical cases or are difficult to use. The duration of the electrocardiographic ventricular complex, on the other hand, can be determined easily on suitable records, and it seems likely that this record of cardiac activity is as closely associated with the state of the myocardium itself, though perhaps not with the general circulation, as the measurement of systole by mechanical means.

The ventricular complex begins with the beginning of the $Q$-wave and ends at the end of the $T$-wave. Because " electrocardiographic ventricular complex duration" is an inconvenient term and because introduction of the word systole makes for ambiguity, it will be referred to in this paper as " $Q-T$ time."

Cheer and $\mathrm{Li}$ (3) have published a formula for the determination of the normal $Q-T$ time in the recumbent position based on measurements from 75 normal men and 43 normal women. Fridericia (6) published a formula for the determination of $Q-T$ time on the basis of measurements on 50 individuals-men, women and children. White and Mudd (7) have published a scattergraph of 50 normal individuals ( $Q-T$ time against the $R-R$ interval) without stating the accurate measurements. Their scatter agrees quite well with 190 cases which they collected from the literature. Bazett (8) has published similar figures from 2 male infants, 2 boys, 12 men, and 19 women. Several records under various conditions were taken on some of his patients. The formulas which he gives apparently include all the measures on these cases, although this is not definitely stated. Miki (9), on the basis of a small group of normals, confirmed Fridericia's formula. Fenn (10) with measurements on 10 patients published a formula which approximated Bazett's. Lian, Golblin and Baraige (11) used a formula without giving the data upon which it was based, which gave a much wider " normal" range of $Q-T$ time at slow normal pulse rates than at rapid normal rates.

In an attempt to use the formulas of Fridericia and Cheer and $\mathrm{Li}$ in the study of $Q-T$ time, it was found that the measurements on our cases in practically all instances exceeded the prediction from these formulas. Because of this it seemed advisable to study the duration in normal individuals again. It was decided to test some characteristics of individuals other than rate, for influence on the $Q-T$ time.

\section{METHOD}

A series of normal individuals was collected comprising 50 males and 54 females. Standard lead electrocardiograms were obtained on a Hindle string galvanometer electrocardiograph with a time marker controlled by a tuning fork. This time marker, by repeated checks against a stop watch, was found to have an error of approximately $13 / 4$ per cent. All figures as given have been corrected for this error. Four more tracings were taken but discarded either because the base line was so irregular that accurate measurement was impossible ( 3 cases), or because 
ventricular extrasystoles were found (1 case). The entire series was presumably normal; it consisted of medical staff, nurses, students and secretarial workers. A physical examination was performed on all cases. It may or may not be significant that they all considered themselves to be in good health, and were not "patients without cardiac disease." All tracings were taken with the subjects supine, but no effort was made to control the extent of previous activity. No effort at selection according to rate or any other characteristic was made, aside from checking for normality. The film speed was increased to about $5 \mathrm{~cm}$. per second with the thought that the increased speed might facilitate accurate measurement. The impression gained was that it did not. In both Leads I and II at least 15 consecutive cardiac cycles, exclusive of the standardization, were recorded. A shorter strip of Lead III was taken. Leads I and II were measured separately. The pulse interval recorded was the average of 15 consecutive $R-R$ intervals. The duration of systole was measured by projecting the film in a photographic enlarger on to graph paper ruled in squares of $1 / 10$ of an inch. It was enlarged so that .01 second on the record corresponded to $1 / 10$ of an inch. It is the author's impression that this makes it possible to measure the record with accuracy as great as the inevitable slight irregularities of the base line will permit. The points were marked on the graph paper and measured later. This prevented any tendency to modify measurements because of a knowledge of previous measurements. No effort was made to be more accurate than .005 second in the location of any point. It is probable that an attempt at greater accuracy is not justified in the great majority of records. No effort has been made to evaluate exactly the error in measurement, but the author believes that it is less than .01 second in suitable records. In the series of 50 males, 15 consecutive complexes were measured in each of the first two leads because of the statement by Lombard and Cope (2) that this was necessary in order to get a true average measurement. The average measurement of the first 5 of each set of 15 was then compared with the average of the 15 . The maximum difference between these averages was .006 second, this difference occurring twice in
50 cases. The average difference was .0018 second. The means, standard deviations and regression formulas were not significantly different. On the basis of this comparison only 5 complexes were measured in each lead in the series of females and the average of 5 used in both series.

Several other data were collected on each subject including height, weight, and the age at the nearest birthday. In the electrocardiogram the axis was determined, the height of the $T$-wave was measured, and measurements of three parts of the ventricular complex were made as follows: first, the time from the beginning of the $Q R S$ complex to the peak of the $R$-wave; second, the time from the peak of the $R$-wave to the peak of the $T$-wave; and third, the time from the peak to the end of the $T$-wave.

The data obtained were treated statistically, the male series slightly more extensively than the female series because some of the factors considered were obviously without influence on the $Q-T$ time in the former series and were therefore not considered in the latter. The method of the statistical work will be outlined only briefly. In the male series Pearsonian linear zero order correlation coefficients were determined between all possible combinations of seven variables. The variables used were the $Q-T$ time, the $R-R$ interval, the electrocardiographic axis, the $T$-wave height, the height, the weight, and the age. Multiple correlations between $Q-T$ time and various combinations of the other variables were computed by Horst's (12) modification of the Doolittle method. Three measures of $Q-T$ time were used-that obtained from Lead I, that obtained from Lead II, and one obtained by selecting whichever $Q-T$ time average measure was the longer from Lead I or II. In each case the average $R-R$ interval and $T$-wave height from the corresponding lead was used.

The female series was treated the same way except that height of the $T$-wave and electrocardiographic axis were not included. The same procedures were carried out with the combined groups except that only Lead II and whichever lead had the longer $Q-T$ time were used, Lead I not being considered separately.

Some calculations were made using the time 
from the peak of the $R$-wave to the peak of the $T$-wave rather than $Q-T$ time.

Scatter diagrams were constructed to ascertain the type of functional relationships between the characteristics. For the purposes of this study it was found that these relationships could be satisfactorily represented by straight lines, and consequently linear correlation analysis was used.

Table I shows the individual measures of $Q-T$

TABLE I

Q-T time (the longer measure of Lead I or II-Average of
5 complexes) and pulse interval (the average of 15
complexes from the corresponding lead)

\begin{tabular}{|c|c|c|c|c|c|c|c|c|c|c|c|}
\hline \multicolumn{6}{|c|}{ Males } & \multicolumn{6}{|c|}{ Females } \\
\hline $\begin{array}{l}\text { 岁 } \\
\text { 营 }\end{array}$ & 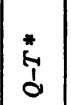 & $\begin{array}{c}\grave{a} \\
\frac{1}{\alpha}\end{array}$ & $\begin{array}{l}\text { 岁 } \\
\text { 息 }\end{array}$ & d & $\underset{\alpha}{a}$ & 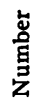 & 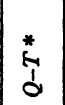 & $\underset{\leftarrow}{+}$ & 岁 & $\stackrel{*}{d}$ & $\underset{\alpha}{\mathbb{\alpha}}$ \\
\hline $\begin{array}{r}1 \\
2 \\
3 \\
4 \\
5 \\
6 \\
7 \\
8 \\
9 \\
10 \\
11 \\
12 \\
13 \\
14 \\
15 \\
16 \\
17 \\
18 \\
19 \\
21 \\
22 \\
23 \\
24 \\
25 \\
26\end{array}$ & \begin{tabular}{|l|}
.376 \\
.344 \\
.367 \\
.402 \\
.369 \\
.347 \\
.368 \\
.377 \\
.379 \\
.388 \\
.367 \\
.369 \\
.345 \\
.364 \\
. .328 \\
.407 \\
.364 \\
.365 \\
.354 \\
. .429 \\
.384 \\
. .382 \\
.365 \\
\end{tabular} & \begin{tabular}{|}
.837 \\
.617 \\
.910 \\
.937 \\
.771 \\
.686 \\
.744 \\
.818 \\
.768 \\
.903 \\
.875 \\
.692 \\
.708 \\
1.081 \\
.813 \\
.969 \\
.756 \\
.724 \\
.814 \\
.964 \\
1.113 \\
.842 \\
.741 \\
.668
\end{tabular} & $\begin{array}{l}27 \\
28 \\
29 \\
30 \\
31 \\
32 \\
33 \\
34 \\
35 \\
36 \\
37 \\
38 \\
39 \\
40 \\
41 \\
42 \\
43 \\
44 \\
45 \\
46 \\
47 \\
48 \\
49 \\
50 \\
51\end{array}$ & $\begin{array}{l}.377 \\
.380 \\
.383 \\
.344 \\
.379 \\
.375 \\
.331 \\
.359 \\
.332 \\
.364 \\
.376 \\
.387 \\
.356 \\
.427 \\
.361 \\
.364 \\
.358 \\
.361 \\
.355 \\
.393 \\
.371 \\
.382 \\
.370 \\
.363 \\
.373\end{array}$ & \begin{tabular}{|r|}
.049 \\
.933 \\
.923 \\
.722 \\
.869 \\
.595 \\
.704 \\
.647 \\
.750 \\
.900 \\
.912 \\
.942 \\
.764 \\
.668 \\
.786 \\
.813 \\
.885 \\
.876 \\
.914 \\
.866 \\
.7556 \\
\end{tabular} & $\begin{array}{r}1 \\
2 \\
3 \\
4 \\
5 \\
8 \\
9 \\
11 \\
12 \\
13 \\
14 \\
15 \\
16 \\
17 \\
18 \\
20 \\
21 \\
22 \\
23 \\
24 \\
25 \\
26 \\
27 \\
28 \\
29\end{array}$ & $\begin{array}{l}.365 \\
.392 \\
.361 \\
.391 \\
.392 \\
.432 \\
.380 \\
.373 \\
.377 \\
.381 \\
.376 \\
.385 \\
.397 \\
.413 \\
.410 \\
.383 \\
.392 \\
.348 \\
.386 \\
.367 \\
.386 \\
.331 \\
.376 \\
.365 \\
.389 \\
.365 \\
.388\end{array}$ & $\begin{array}{l}.713 \\
.853 \\
.698 \\
.815 \\
.810 \\
. .765 \\
.788 \\
.798 \\
.807 \\
.804 \\
.793 \\
.8753 \\
.897 \\
.888 \\
.717 \\
.777 \\
.873 \\
.754 \\
.679 \\
.735 \\
.8991 \\
.847 \\
.765 \\
.955\end{array}$ & $\begin{array}{l}50 \\
51 \\
52 \\
53 \\
54 \\
55 \\
56 \\
57 \\
58 \\
59\end{array}$ & \begin{tabular}{|l|}
.391 \\
.386 \\
.378 \\
.377 \\
.372 \\
.386 \\
.402 \\
.388 \\
.405 \\
.370 \\
.380 \\
.384 \\
.368 \\
.368 \\
.443 \\
.376 \\
.382 \\
.386 \\
.362 \\
.373 \\
.353 \\
.387 \\
.415 \\
.422 \\
.356 \\
. .396 \\
.363
\end{tabular} & $\begin{array}{c}.729 \\
.747 \\
.856 \\
.833 \\
.793 \\
.761 \\
.902 \\
.924 \\
.813 \\
.762 \\
.867 \\
.818 \\
.694 \\
.894 \\
1.256 \\
.943 \\
.914 \\
.916 \\
.876 \\
.779 \\
.769 \\
1.011 \\
1.118 \\
.823 \\
.807 \\
.694\end{array}$ \\
\hline
\end{tabular}

*Q-T $=Q-T$ time in seconds.

$\dagger R-R=R-R$ interval in seconds.

time and $R-R$ interval; in each case these measures are taken from Lead I or II, the lead with the longer average $Q-T$ time being used. These are the original measurements upon which the recommended formula is based. Some of the other data considered are summarized in Table II.

\section{DISCUSSION}

The regression formulas obtained in the correlation analysis express the relationship between characteristics, and therefore are a device for estimating one characteristic from one or more other characteristics.

Two selections are to be made-first, the measure of $Q-T$ time to be predicted, and second, the other individual characteristics to be used in making the prediction. As stated above three measures of $Q-T$ time and two other measures of part

TABLE II

Means, standard deviations and correlation coefficients

\begin{tabular}{|c|c|c|c|c|c|c|c|c|}
\hline \multirow{2}{*}{ Variable } & \multirow{2}{*}{ Sex } & \multirow{2}{*}{ Lead } & \multirow{2}{*}{ Mean } & \multirow{2}{*}{$\begin{array}{l}\text { Stand- } \\
\text { ard } \\
\text { devia- } \\
\text { tion }\end{array}$} & \multicolumn{4}{|c|}{$\begin{array}{l}\text { Zero order correlation } \\
\text { coefficients }\end{array}$} \\
\hline & & & & & $R-R$ & Age & Height & Weight \\
\hline$Q-T$ time, seconds & $\begin{array}{l}\mathbf{M} \\
\mathbf{M} \\
\mathbf{M} \\
\mathbf{F} \\
\mathbf{F} \\
\mathbf{F}\end{array}$ & $\begin{array}{l}\mathbf{C}^{*} \\
\text { I } \\
\text { II } \\
\mathbf{C} \\
\text { I } \\
\text { II }\end{array}$ & $\begin{array}{l}.3723 \\
.3626 \\
.3706 \\
.3832 \\
.3748 \\
.3822\end{array}$ & $\begin{array}{l}.0213 \\
.0209 \\
.0225 \\
.0178 \\
.0199 \\
.0199\end{array}$ & $\begin{array}{r}+.827 \\
+.796 \\
+.792 \\
+.738 \\
+.627 \\
+.708\end{array}$ & $\begin{array}{l}+.005 \\
\pm .000 \\
+.029 \\
-.077 \\
-.038 \\
-.038\end{array}$ & $\begin{array}{r}+.212 \\
+.208 \\
+.211 \\
+.123 \\
+.235 \\
+.312\end{array}$ & $\begin{array}{l}+.061 \\
+.156 \\
+.008 \\
+.176 \\
+.157 \\
+.228\end{array}$ \\
\hline$R-T_{p}, \dagger$ seconds & $\begin{array}{l}\mathbf{M} \\
\mathbf{M} \\
\mathbf{F} \\
\mathbf{F}\end{array}$ & $\begin{array}{l}\text { I } \\
\text { II } \\
\text { I } \\
\text { II }\end{array}$ & $\begin{array}{l}.2397 \\
.2449 \\
.2615 \\
.2638\end{array}$ & $\begin{array}{l}.0183 \\
.0178 \\
.0171 \\
.0175\end{array}$ & $\begin{array}{r}+.834 \\
+.847 \\
+.613 \\
+.600\end{array}$ & $\begin{array}{r}-.008 \\
+.028 \\
+.016 \\
-.008 \\
\end{array}$ & $\begin{array}{r}+.226 \\
+.169 \\
+.183 \\
+.207\end{array}$ & $\begin{array}{r}+.038 \\
+.019 \\
+.119 \\
+.146\end{array}$ \\
\hline$Q-T_{p \ddagger}$ & $\mathbf{M}$ & I & .2750 & .0184 & +.783 & -.016 & +.236 & +.120 \\
\hline $\begin{array}{l}R-R \text { pulse interval, } \\
\text { seconds }\end{array}$ & $\begin{array}{l}\mathbf{M} \\
\mathbf{M} \\
\mathbf{M} \\
\mathbf{F} \\
\mathbf{F} \\
\mathbf{F}\end{array}$ & $\begin{array}{l}\text { C } \\
\text { I } \\
\text { II } \\
\text { C } \\
\text { I } \\
\text { II }\end{array}$ & $\begin{array}{l}.8207 \\
.8274 \\
.8141 \\
.8281 \\
.8311 \\
.8264\end{array}$ & $\begin{array}{l}.1145 \\
.1133 \\
.1140 \\
.1045 \\
.0992 \\
.1066 \\
\end{array}$ & & $\begin{array}{l}-.170 \\
-.138 \\
-.135 \\
-.265 \\
-.217 \\
-.276 \\
\end{array}$ & $\begin{array}{r}+.095 \\
+.015 \\
+.049 \\
+.285 \\
+.278 \\
+.327 \\
\end{array}$ & $\begin{array}{r}+.048 \\
+.042 \\
+.019 \\
+.167 \\
+.173 \\
+.174 \\
\end{array}$ \\
\hline Age, years & $\mathbf{M}$ & & $\begin{array}{l}28.76 \\
27.74\end{array}$ & $\begin{array}{l}4.80 \\
6.06\end{array}$ & & & $\begin{array}{r}+.059 \\
-.261 \\
\end{array}$ & $\begin{array}{l}+.166 \\
+.188\end{array}$ \\
\hline Height, $\mathrm{cm}$. & $\mathbf{M}$ & & $\begin{array}{l}178.9 \\
162.7\end{array}$ & $\begin{array}{l}6.2 \\
5.7\end{array}$ & & & & $\begin{array}{r}+.613 \\
+.500\end{array}$ \\
\hline Weight, kgm. & $\underset{\mathbf{F}}{\mathbf{M}}$ & & $\begin{array}{l}75.10 \\
56.38\end{array}$ & $\begin{array}{l}9.71 \\
6.30\end{array}$ & & & & \\
\hline
\end{tabular}

${ }^{*} C=$ the lead (I or II) with the longer $Q-T$ time.

$\dagger R-T_{p}=$ the time from the peak of $R$ to the peak of $T$. $\ddagger Q-T_{p}=$ the time from the beginning of $Q R S$ to the peak of $T$.

of the electrocardiographic ventricular complex were considered. The $Q-T$ time in Lead II is longer than in Lead $I$ in the majority of cases and its average is larger (Table II). In some instances, however, the $Q-T$ time is definitely longer in Lead I than in Lead II. If this divergence is marked and the rates in the two leads are approximately the same, it is found that the Lead II measure is markedly shorter than the prediction. The obvious explanation for this finding is that part of the ventricular complex is isoelectric in Lead II, either the beginning of the $Q R S$ or the end of the $T$. In this series most of the cases in which the duration in Lead I was longer had a $Q$-wave in Lead I but not in Lead II. This suggests that the first portion of the electrocardiographic ventricular complex is isoelectric in Lead II in these cases. Probably the discrepancies between the $Q-T$ time measures are all due to isoelectric phases of the complex in one lead or the other if the rates are the same. This 
is a source of error that can be partially ruled out by taking the longer of the two measures, regardless of the lead in which it occurs. When the beginning of $Q R S$ is isoelectric in one lead and the end of $\mathrm{T}$ isoelectric in another lead the total $Q-T$ time would not be found by selecting the longer of the two. On the basis of the theory of Einthoven's triangle (precordial leads were not taken in this series) any electric effect in the heart must be registered in two of three leads, and therefore one of the three leads would necessarily show deviations from the isoelectric line at both ends of the ventricular complex. In occasional instances this might be Lead III. The $Q-T$ time in Lead III was measured in all cases in which the longer of the measures from the first two leads showed a significant negative deviation from prediction. In no instance was the measure found to be longer in Lead III. It is probably advisable to choose the longest $Q-T$ in any lead, however, in measuring the $Q-T$ time, because presumably we want to measure the total duration of ventricular electrical activity. In both the male and female series the correlation between $Q-T$ time and pulse interval is slightly higher when the longer measure between Leads I and II is used than when either Lead I or II measures are used alone (Table II). The mean of the $Q-T$ measure is only slightly longer when the longer of the two $Q-T$ measures is used (Table II).

As mentioned previously, the $Q-T$ time was divided into three parts, that is, the time from the peak of $R$ to the peak of $T$ and the time preceding and the time following this interval. The primary reason for this was to determine whether the measurement from the peak of $R$ to the peak of $T$ could be used to greater advantage than the total $Q-T$ time. It is easier to obtain an accurate measure because both points are relatively clean cut. If this or some other measure of the ventricular complex could be predicted with greater accuracy than $Q-T$ time a new problem as to its usefulness would be presented. The correlation coefficients between the measurements between the peaks of the $R$ and $T$-waves and the pulse interval are somewhat higher in males and lower in females than the corresponding correlation coefficients between $Q-T$ time and pulse in- terval (Table II). This indicates that no definite increase in accuracy can be obtained by using the distance between the peak of $R$ and the peak of $T$ instead of the $Q-T$ time. The measurement from the beginning of $Q R S$ to the peak of $T$ is also no better than $Q-T$ time in its correlation with pulse interval (Table II). Meakins (13) studied the interval from the end of the $Q R S$ to the end of $T$ but this measure is not considered here because of the difficulty in measuring it. From these studies it seems advisable to use a prediction formula using the longest $Q-T$ time from any lead. In this series, Lead III offered no advantage so that the longer of Leads I and II was used. Three formulas were developed using this $Q-T$. time measure and the pulse interval. For the male series the formula is

$$
\overline{Q-T}=.1536 R-R+.2462
$$

in which $Q-T=Q-T$ time and $R-R=$ pulse interval. The standard error of estimate of $Q-T$ is .012 second. For the female series the formula is

$$
\overline{Q-T}=.1259 R-R+.2789
$$

and the standard error of estimate is .014 second. For the two groups together the formula is

$$
\overline{Q-T}=.1464 R-R+.2572
$$

and the standard error of estimate is .014 second.

To facilitate comparison of these formulas they have been plotted (Figure 1). It will be noted that the predicted or average $Q-T$ time for corresponding pulse intervals is longer in females than in males. With a pulse interval of 1.10 seconds (rate 55) the predicted $Q-T$ time for females is .002 second longer than for males, while with a pulse interval of .60 second (rate 100) it is .016 second longer. Statistical criticism shows that the difference between the male and female formulas is great enough to indicate a high probability of true sex difference. (See below.) This concludes the consideration of the choice of the measure of $Q-T$ time to be predicted.

The prediction of $Q-T$ time from pulse interval alone is discussed above. Other measurements on each individual are height, weight, age, height of the $T$-wave, and electrical axis. In the male 


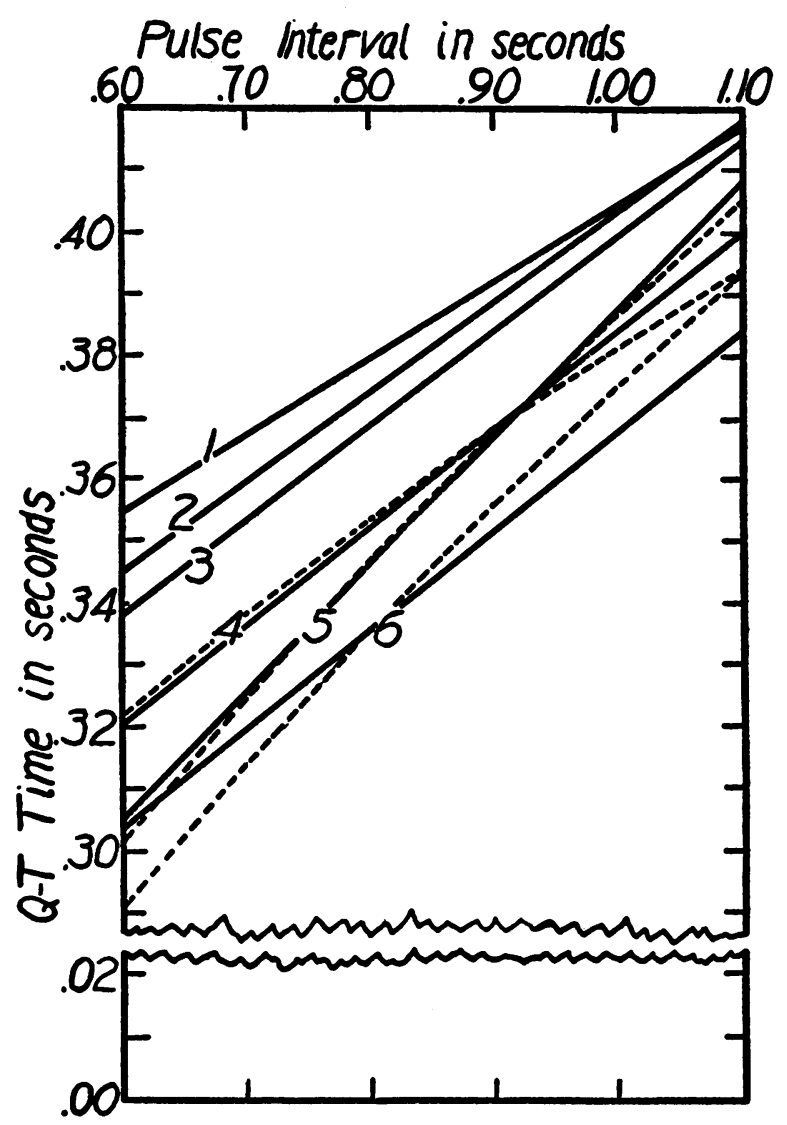

Fig. 1. Representation of Formulas for Prediction of $Q-T$ Time from Pulse Interval (Regression LINES).

Lines 1 to 3 are from the author's series. Number 1-females: $\overline{Q-T}=.1259 R-R+.2789$, in which $\overline{Q-T}$ $=Q-T$ time in seconds and $R-R=$ pulse interval in seconds. Number 2-sexes together : $\overline{Q-T}=.1464 R-R$ +.2572 . Number 3-males: $\overline{Q-T}=.1536 R-R+.2462$. The curved line formulas as published by other workers are represented by dotted lines 4 to 6 and the straight line formulas developed from the same data are represented by solid lines 4 to 6 . Number 4 -Fridericia (6)-sexes together-straight line: $\overline{Q-T}=.1599 \quad R-R+.2245$; curved line: $S=8.22 \cdot \sqrt[3]{P}$, in which $S=Q-T$ time and $P=$ pulse interval, both in hundredths of seconds. Number 5-Cheer and $\mathrm{Li}$ (3)-females-straight line: $\overline{Q-T}=.2079 R-R+.1799$; curved line $: S=.3877 \sqrt{P}$, in which $S=Q-T$ time and $P=$ pulse interval, both in seconds. Number 6-Cheer and $\mathrm{Li}$-males-straight line : $\overline{Q-T}=.1605 R-R+.2069$; curved line $: S=374 \sqrt{P}$.

series multiple correlations with these five observations as well as pulse interval were computed in an effort to increase the accuracy of the prediction of $Q-T$ time. Height of the $T$-wave and electrical axis were dropped from consideration at once because their influence on the $Q-T$ time was obviously negligible. This judgment was made on the basis of a comparison of the partial $\beta$ regression coefficient of each variable with its standard error. The values of these in Lead II are given in Table III. Some insignificant differences in the relationships are found when Lead $I$ is used.

TABLE III

Partial $\beta$ regression coefficients and their standard errors (Lead II)

\begin{tabular}{|c|c|c|c|c|c|c|}
\hline \multirow[b]{3}{*}{$\begin{array}{c}\text { Independent variables } \\
\text { used in estimating } \\
Q-T \text { time }\end{array}$} & \multicolumn{4}{|c|}{ Male } & \multirow{2}{*}{\multicolumn{2}{|c|}{$\frac{\text { Female }}{5 \text { variables }}$}} \\
\hline & \multicolumn{2}{|c|}{7 variables } & \multicolumn{2}{|c|}{5 variables } & & \\
\hline & $\beta$ & $\sigma_{\beta}$ & $\boldsymbol{\beta}$ & $\sigma_{\beta}$ & $\boldsymbol{\beta}$ & ${ }^{\sigma_{\beta}}$ \\
\hline 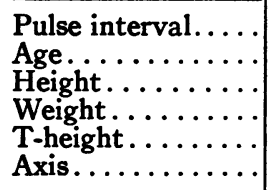 & $\begin{array}{r}.792 \\
.193 \\
.296 \\
-.197 \\
.072 \\
.018\end{array}$ & $\begin{array}{l}.084 \\
.086 \\
.106 \\
.111 \\
.092 \\
.093\end{array}$ & $\begin{array}{r}.809 \\
.173 \\
.295 \\
-.214\end{array}$ & $\begin{array}{l}.081 \\
.082 \\
.101 \\
.102\end{array}$ & $\begin{array}{l}.720 \\
.192 \\
.125 \\
.004\end{array}$ & $\begin{array}{l}.105 \\
.111 \\
.125 \\
.121\end{array}$ \\
\hline
\end{tabular}

In the author's group of males, height, weight and age increased the accuracy of prediction to some extent, but the significance of these characteristics for this purpose in the general population was in doubt. Therefore multiple correlations with these variables were computed in the female series. The evidence from this group of females indicates that height, weight and age have little if any effect on $Q-T$ time. When a formula is computed with the sexes together, the correlations of $Q-T$ time with age, height and weight change from positive to negative which indicates that none of them has as great an influence as sex does, even though this is slight. This entire group is not very satisfactory from the standpoint of age, the range being from 20 to 48 years, with only 8 of the 104 patients over 35 years old. The evidence from this study does not demonstrate that weight, $T$-wave height, and electrical axis influence $Q-T$ time. If age and height of the individual have any influence it is slight and of little use in the estimation of $Q-T$ time. In addition it was found that height, weight and age do not increase the accuracy of prediction of other measures of the ventricular complex mentioned above more than they do the prediction of $Q-T$ time. In no case is the standard error of estimate of $Q-T$ time from a formula 
drawn from multiple correlations more than .001 second smaller than the standard error of estimate from the corresponding formula using pulse interval alone.

The duration of the ventricular complex has never been predicted with complete accuracy from any set of variables because it does not vary in constant relation with any known combination of characteristics. Predictions will probably be subject to an error of about .01 second because of error in measurement in individual cases. The error in predicting $Q-T$ time from the pulse interval is less than .01 second in more than half the cases. The errors in the remaining cases range up to .04 second with few errors in excess of .03 second. The usefulness of the $Q-T$ time measure is impaired because of this wide deviation of a few cases, as White and Mudd (7) have shown. Further study is advisable to attempt to find other characteristics which will aid in the prediction of $Q-T$ time.

This study is of interest chiefly because of the marked difference between the normal values for $Q-T$ time as determined from this and previous series. Fridericia's (6) formula is:

$$
S=8.22 \sqrt[3]{ } P
$$

in which $S=Q-T$ time and $P=$ pulse interval, both in units of .01 second. Cheer and $\mathrm{Li}(3)$, Bazett (8) and Fenn (10) used formulas of the form:

$$
S=K \sqrt{P}
$$

in which $S=Q-T$ time, $K=\mathrm{a}$ constant, and $P=$ the pulse interval. Cheer (3) found $K$ to be .374 in males and .3877 in females. Bazett (8) found it to be .37 in males and .40 in females. Fenn (10), on a mixed group, found $K$ to be .39 . These formulas are obviously curved lines when plotted. The curves, however, are slight, approximating straight lines through the normal range of pulse rates in adults. These writers have apparently used this type of curved line regression formula not because the relationship between $Q-T$ time and pluse interval is a curved line, but because the increase of $Q-T$ time with pulse interval is not proportional. As a number increases, its square root and cube root also increase but less rapidly. The increase of $Q-T$ time with pulse interval bears a more nearly constant proportion to the increase of either the square root or cube root of pulse interval than to the increase of pulse interval itself. Fridericia gives mathematical justification for the use of the cube root type of formula rather than the square root type in his series of cases. Cheer and $\mathrm{Li} \mathrm{(3)}$ state that the results of their studies confirm the square root type of formula without giving mathematical proof. The curved line regression formulas of Fridericia and Cheer and $\mathrm{Li}$ have been plotted (Figure 1). To make this type of formula accurate in all cases it would be necessary to use roots which are not integral numbers, which would complicate its use somewhat. The straight line type of formula as used above in the author's series (plotted in Figure 1) is adjustable to any data of this type.

The data used by Fridericia and by Cheer and $\mathrm{Li}$ in calculating their curved line formulas have been used in calculating formulas of the straight line type. These have been plotted (Figure 1). Fridericia did not divide his cases by sex, and it was not done in calculating straight line formulas because of the relatively small number of cases. As might be expected from his careful development the straight line formula approximates Fridericia's cube root formula, the two lines crossing twice (Figure 1). Between rates of 55 and 100 the greatest difference of prediction between the straight line and cube root formula is .003 second at a rate of 55. The standard errors of estimate of $Q-T$ time of the two are practically identical. In the male series of Cheer and $\mathrm{Li}$ the slope of his curved line square root formula is definitely steeper than the slope of the straight line regression formula developed from the same data (Figure 1). The lines cross at a pulse interval of .80 (rate 75). At a pulse interval of 1.10 (rate 55) the prediction by the straight line formula is .010 second shorter than with the square root formula. At a pulse interval of .60 (rate 100) the prediction is .013 second longer by the straight line formula than by the square root formula. In the female series of Cheer and $\mathrm{Li}$, which is smaller, the correspondence between the square root formula and the straight line formula is close with the lines crossing twice and a maximum difference between the two formulas in the range of normal 
heart rates of .002 second at a rate of 100 . It should be noted, however, in this connection that the average rate of the females is rather high and that the relatively few cases in the slower rate brackets affect the slope of the curve heavily. Perhaps this may account for the marked divergence of the straight line formulas at the slower rates, while they cross at a rate of slightly greater than 100 . It will be noted that while the straight line formula of this series of females approximates the square root formula, the straight line formula of Cheer and Li's males is practically parallel with, although lower than, the straight line formula from Fridericia's cases.

The difference in prediction by the various formulas is striking. This expresses a difference between the measurements of $Q-T$ time as compared with pulse interval in the three series of cases. There are three possible explanations for this difference: first, technical considerationspolarization in the circuit or inaccuracy in the time registration in some of the machines used; second, a difference between observers as to what constitutes the duration of the ventricular complex; and third, an actual difference between the different series of individuals. Polarization is not present in the author's records and, since it would probably tend to lengthen the $Q-T$ time, is probably not an explanation for the fact that other measurements are shorter. In regard to the time registration nothing can be said except that the timer used in this series has been checked as stated above. The location of the end of the $T$-wave is sufficiently uncertain so that some individual difference in measurement might enter, but it seems almost impossible that this should be great enough to account for the discrepancy. As to the third possibility, that the difference is due to differences in the individuals used, it may be said that the chance that the differences between the three series represent errors incident to random sampling from the same population is so remote as to be discarded. The fact that each of the three series was drawn from different parts of the world from persons with different racial characteristics and modes of life may be important. No conclusions can be drawn regarding the reason for the discrepancy between the two prediction formulas on the basis of present data.
Cheer and $\mathrm{Li}$ found that females had longer average $Q-T$ time measurements for corresponding heart rates than males. This was also the case in Fridericia's series, although the small series does not justify separation into sexes in calculating prediction formulas. Bazett also noted a sex difference as stated above. When the straight line formulas (Figure 1) of Cheer and $\mathrm{Li}$ are compared a different relationship is found to exist between the sexes than in the case in the author's series, although in both instances the prediction for females is longer than for males at corresponding rates. The male and female predictions approximate each other at a pulse interval of .60 second (rate 100) but are widely divergent (.027 second) at a pulse interval of 1.10 (rate 55). While the two lines of Cheer and $\mathrm{Li}$ converge in the range of rapid normal rates, the two lines of the author's sample converge in the slow normal rates. These findings support the conclusions made above that a true sex difference exists but no decision can be made as to whether this difference is greater for one heart rate than another. In other words, the difference between the heights of the sex lines is significant but the difference between the slopes is not (Figure 1).

In using either the curved or straight line type of formula a prediction of $Q-T$ time for any given rate may be made and the deviation of the measured duration in a given case from the prediction for that rate obtained. It seems that this method gives a clearer, more easily handled conception than the calculation of " $K$ " for each case and the determination of the deviation of the individual " $K$ " from the normal " $K$." This determination of " $K$ " gives the deviation of measure from prediction a value in proportion to the size of the prediction, but the same result may be obtained by expressing the deviation of the measured duration from the predicted duration as a percentage of the prediction as was done by Berliner (14). However, there is no evidence at the present time to show that the percentage deviation is more significant than the absolute deviation.

The use of the formulas may be simplified by constructing a table. The value for each pulse interval is determined and entered opposite the pulse interval or the corresponding pulse rate. If it is desired to express deviations from prediction 
as a percentage, the table may be amplified by another column showing the percentage of the prediction represented by .01 second and from this the percentage deviation of any measure from the prediction can be readily calculated. Table IV is such a table.

TABLE IV

Predictions of Q-T time for normal heart rates

\begin{tabular}{c|c|c|c}
\hline \hline \multirow{2}{*}{ Pulse interval } & \multirow{2}{*}{ Heart rate } & \multicolumn{2}{|c}{$Q-T$ time } \\
\cline { 2 - 4 } & & Male & Female \\
\cline { 2 - 4 } seconds & per minute & seconds & seconds \\
.60 & 100 & .338 & .354 \\
.65 & 92 & .346 & .361 \\
.70 & 86 & .354 & .367 \\
.75 & 80 & .361 & .373 \\
.80 & 75 & .369 & .380 \\
.85 & 71 & .377 & .386 \\
.90 & 67 & .384 & .392 \\
.95 & 63 & .392 & .399 \\
1.00 & 60 & .400 & .405 \\
1.05 & 57 & .407 & .411 \\
1.10 & 55 & .415 & .417 \\
\hline
\end{tabular}

\section{SUMMARY}

1. The most accurate formulas for the prediction of the duration of the electrocardiographic ventricular complex ( $Q-T$ time) from measurements of pulse interval in a series of 50 normal males and 54 normal females are: for males,

$$
\overline{Q-T}=.1536 R-R+.2462
$$

and for females,

$$
\overline{Q-T}=.1259 R-R+.2789
$$

in which $Q-T=$ duration of electrocardiographic systole, and $R-R=$ pulse interval. A table is provided which simplifies the use of these formulas.

2. The use of age, height, and weight of the individual, and height of the $T$-wave and axis of the electrocardiogram does not appreciably increase the accuracy of prediction of the duration of the electrocardiographic ventricular complex.

3. Other workers have found the duration of the electrocardiographic ventricular complex to be shorter for corresponding pulse rates. The reason for this difference is not apparent, but several possible explanations are discussed.
The author wishes to express appreciation for advice and criticism regarding statistical methods to Professor T. O. Yntema.

\section{BIBLIOGRAPHY}

1. Wiggers, C. J., and Katz, L. N., The contour of the ventricular volume curves under different conditions. Am. J. Physiol., 1922, 58, 439.

2. Lombard, W. P., and Cope, O. M., The duration of the systole of the left ventricle of man. Am. J. Physiol., 1926, 77, 263.

3. Cheer, S. N., and Li, R. C., Studies on the electrical systole (" $Q-T$ " interval) of the heart. I. The duration of electrical systole in normal Chinese. Chinese J. Physiol., 1930, 4, 191.

4. Bartos, E., and Burstein, J., Can variations in ventricular systole be determined from electrocardiogram deflections? J. Lab. and Clin. Med., 1924, 9, 217.

5. Bazett, H. C., and Sands, J., The significance of measurements of the duration of systole. Ann. Clin. Med., 1926, 5, 190.

6. Fridericia, L. S., Die Systolendauer im Elektrokardiogramm bei normalen Menschen und bei Herzkranken. Acta med. Scandinav., 1920-21, 53, 469.

7. White, P. D., and Mudd, S. G., Observations on the effect of various factors on the duration of the electrical systole of the heart as indicated by the length of the $Q-T$ interval of the electrocardiogram. J. Clin. Invest., 1929, 7, 387.

8. Bazett, H. C., An analysis of the time-relations of electrocardiograms. Heart, 1919, 7, 353.

9. Miki, Y., Experimentelle und klinische Untersuchungen über die Dauer des K-Ekg (Kammer-Elektrokardiogramms). Ztschr. f. d. ges. exper. Med., 1922, 27, 323.

10. Fenn, G. K., Studies in the variation of the length of the $Q-R-S-T$ interval. Arch. Int. Med., 1922, 29, 441.

11. Lian, C., Golblin, V., and Baraige, Diagnostic et Valeur Séméiologique de l'Allongement et du Raccourcissement de la Systole Ventriculaire. Presse méd., 1934, 42, 787.

12. Horst, P., A general method for evaluating multiple regression constants. J. Am. Statistical A., 1932, 27, 270.

A short method for solving for a coefficient of multiple correlation. Ann. Math. Statistics, 1932, $3,40$.

13. Meakins, J., Prolongation of the " $S-T$ " interval of the ventricular complex as shown by the electrocardiograph. Arch. Int. Med., 1919, 24, 489.

14. Berliner, K., Observations on the duration of the electrical systole of the heart, with special reference to the effect of digitalis. Am. Heart J., 1931, $7,189$. 